\title{
Correspondence
}

\section{TO THE EDITOR, British Journal of Venereal Diseases}

\section{Penicillinase-producing Neisseria gonorr- hoea in Jakarta, Indonesia}

Sir,

Between 30 April 1981 and 30 April 1982, 156 cases of gonorrhoea were confirmed by culture in the department of microbiology of the Medical Faculty, University of Indonesia. Of these cases, 39 were due to infection with penicillinase-producing Neisseria gonorrhoeae (PPNG). No PPNG strains had been detected in this department before April 1981. All 156 cases occurred in Indonesian patients, both male and female. The first impression was that men seemed to be more affected by PPNG infections than women (table I). Statistically the difference was not significant at the $1 \%$ level $\left(\chi^{2}=0.42, P<0 \cdot 5\right)$. Does this imply that men and women run a similar risk of developing PPNG infections?

Isolation and identification of PPNG and non-PPNG strains were carried out according to standard methods. The minimum inhibitory concentration of

\section{TO THE EDITOR, British Journal of Venereal Diseases}

Changes in intravascular kininogen during the Jarisch-Herxheimer reaction in secondary syphilis

Sir,

The pathogenesis of the JarischHerxheimer reaction (JHR) after the treatment of syphilis remains obscure. It has been attributed to the release of treponemal breakdown products and release of endogenous leucocyte pyrogen 1 after the administration of treponemicidal drugs. Loveday ${ }^{2}$ and others ${ }^{3}$ have reported falls in early components of the classical pathway of the complement system which paralleled the severity of the preceding JHR. These workers proposed a scheme for the mode of activation of complement, kinin formation, and other inflammatory mediators and their possible relation to the clinical features of the JHR. We report

penicillin was measured by a plate dilution method. All PPNG strains showed resistance to $128 \mu \mathrm{g} / \mathrm{ml}$ penicillin $\mathrm{G}$. Further testing of higher concentrations of penicillin could not be performed since these 39 PPNG strains did not remain viable. Several PPNG strains collected later (after April 1982) were tested at higher concentrations of penicillin (table II); none

of the 14 PPNG strains showed any inhibition of growth on 10-unit penicillin discs.

$$
\text { Yours faithfully, }
$$
$S$ Josodiwondo

Department of Microbiology, Medical Faculty, University of Indonesia, Pegangsaan Timur 16, Jakarta, Indonesia.

TABLE I Number of PPNG infections diagnosed between 30 April 1981 and 30 April 1982

\begin{tabular}{llll}
\hline Patients' sex & $\begin{array}{l}\text { PPNG } \\
\text { strains }\end{array}$ & $\begin{array}{l}\text { Non-PPNG } \\
\text { strains }\end{array}$ & $\begin{array}{l}\text { Total No } \\
\text { of cases }\end{array}$ \\
\hline Male & 37 & 105 & 142 \\
Female & 2 & 12 & 14 \\
Total & 39 & 117 & 156 \\
\hline
\end{tabular}

TABLE II Minimum inhibitory concentrations (MICs) of penicillin for 14 PPNG strains

\begin{tabular}{lllllll}
\hline & \multicolumn{7}{l}{ MIC of penicillin $(\mu \mathrm{g} / \mathrm{ml}):$} \\
\cline { 2 - 7 } & 128 & 256 & 1024 & 2048 & 4096 \\
\hline PPNG Strains & 3 & 1 & 1 & 1 & 8 \\
\hline
\end{tabular}

changes in intravascular kininogen in six patients with early secondary syphilis and in one control subject in the first eight hours after the initial therapeutic dose of antibiotics.

Six seropositive patients (aged 26-66 years) with secondary syphilis who had a typical rash and minimal or no lymphadenopathy were studied. After being given 600000 units of procaine penicillin (Distaquine suspension) by intramuscular injection they were observed for at least eight hours. Before treatment pulse, blood pressure, temperature, and clinical features were recorded and blood samples taken. Treatment was given and observations repeated and specimens taken at $1 / 2,1,1 \frac{1}{2}, 2,3,4,6$, and 8 hours. Each blood sample was heparinised (100 U heparin/10 ml blood) avoiding contact with glass, and the plasma was separated within 30 minutes and frozen at $-70^{\circ} \mathrm{C}$.

Assay of plasma kininogen was expressed as bradykinin in $\mu \mathrm{mol} / 1$ released from 408 plasma kininogen by trypsin. The kinit released was assayed on the isolated rat uterus. ${ }^{4}$ Immunoglobulin assays for $\mathrm{IgG}^{\mathrm{D}}$ $\operatorname{IgM}$, and $\operatorname{IgA}$ were carried out using standard Hyland Immunoplates; results. were expressed as percentages of those pooled for normal human serum.

The six patients showed varying degrees of clinical change after the start of treatment. In case 1 the patient had a severes JHR; the rash increased in intensity and the temperature rose to $38 \cdot 8^{\circ} \mathrm{C}$ and the pulse rate to 100 /minute; a slight fall in pulse rate produced a subsequent rise in blood pressure. This patient developed rigors, and observations and collection of bloof samples were stopped at the six-hourk interval. In case 2 the patient had a similafe reaction with an increase in the intensity of the rash, a rise in temperature to $38.8^{\circ} \mathrm{C}$, an increase in pulse rate to $110 /$ minute, ando a similar but more pronounced change in $\bar{p}$ blood pressure than in case 1. Both these patients reported severe symptom 伿 